\title{
Clinical Features of Acute Respiratory Infections Associated with the Streptococcus Milleri Group in the Elderly
}

\author{
EIICHIRO SUGIHARA, YASUKO KIDO**, MASAKI OKAMOTO, TAKESHI KOYANAGI*, \\ TAKASHI NIIZEKI*, NAOTOSHI HIROTA*, SHUWA MINAMI, TAKASHI KINOSHITA**, \\ YASUKO UEHARA, HIDEYUKI KOGA, NORIYUKI ONO*, TORU RIKIMARU** \\ AND HISAMICHI AIZAWA**
}

\begin{abstract}
National Kyushu Respiratory Clinical and Reseach Center, Fukuoka 810-8563,
*Department of Internal Medicine, Chikugo City Hospital, Chikugo 833-0041 and

** Department of Medicine, Kurume University Scool of Medicine, Kurume 830-0011, Japan
\end{abstract}

\begin{abstract}
Summary: The Streptococcus milleri group are becoming increasingly recognized as important pulmonary pathogens which may lead to the development of empyema or lung abscesses. Although several small series have been reported, the clinical and laboratory features of Streptococcus milleri infection have yet to be fully characterized in the elderly. We retrospectively examined the clinical features of 19 patients with Streptococcus milleri pulmonary disease who were admitted to our hospital between 2000 and 2002, based on their clinical records and laboratory data. The microbiological diagnosis was based on the results of quantitative sputum culture and other invasive procedures, including transthoracic needle aspiration or bronchoscopic examinations. There were thirteen cases of pneumonia, two of contaminant pneumonia and pleuritis, one of bronchitis, two of pulmonary abscess, and one of empyema. The patients ranged in age from 65 to 91 . The most common symptoms at presentation were shortness of breath, coughing, sputum, and weight loss. An underlying disease existed in 14 of the 19 cases. We conclude that the Streptococcus milleri group is a more important cause of pulmonary infections than has been previously recognized.
\end{abstract}

Key words streptococcus milleri group, acute respiratory infection

\section{INTRODUCTION}

The term "Steptococcus milleri group" refers to a heterogeneous group of streptococci which are becoming increasingly recognized as clinical important pathogens. Streptococci that colonize the mouth and upper respiratory tract are generally harmless commensals [1]. These organisms are capable of causing disease (e.g., endocarditis or dental caries) and even death, especially when they gain entrance to host sites that are usually sterile [2], but they are rarely the cause of community-acquired pulmonary infections. In general, these oral commensals are distinct from the obvious pathogen Streptococcus pneumoniae, which may be found in the mouth and upper respiratory tract of healthy persons but which frequently causes acute pulmonary infections [3]. However, one group of commensal oral streptococci, the Streptococcus milleri group, has been identified as an important cause of pulmonary empyema and abscesses [4,5]. There are numerous reports documenting the importance of the Streptococcus milleri group in respiratory infections [6-8].

We report the characteristics of 19 patients of advanced age with Streptococcus milleri pulmonary infections. The purpose of this study was to contribute to a better understanding of the importance of members of the Streptococcus milleri group as respiratory pathogens, by examining the epidemiological and clinical features of thoracic infections 
caused by these pathogens in the elderly, especially in those of very advanced age.

\section{PATIENTS AND METHODS}

We retrospectively studied the clinical records of 19 patients of advanced age (over 65 years) who were diagnosed with acute respiratory infections caused by the Streptococcus milleri group and who had been admitted to our hospital between January 2000 and December 2002.

We clinically classified these acute respiratory infections as pneumonia, lung abscess, empyema or acute bronchitis. Specimens from patients were directly examined using the Gram stain and then plated onto a range of non-selective and enriched media for aerobic and anaerobic incubation. The plates were incubated at $37^{\circ} \mathrm{C}$ for up to five days. Any colonies with the colonial appearance and typical caramel odour of Streptococcus milleri were subcultured in carbon dioxide to check for enhanced growth.
For the diagnosis of acute respiratory infections caused by Streptococcus milleri, we adopted the Japanese guideline for Streptococcus milleri infections [9,10]; that is, Streptococcus milleri should be detected at a rate of at least $10^{6} \mathrm{CFU} / \mathrm{ml}$ of purulent sputum, gram-positive cocci phagocyted by polymorphonuclear leukocytes are detected, no other gram-positive cocci are isolated, and the infection subsides after the administration of antibiotics to which these pathogens are sensitive. When Streptococcus milleri was detected directly in a pleural effusion or transbronchial aspiration biopsy specimen, we diagnosed the patient as having a Streptococcus milleri infection. Furthermore we evaluated the severity of infection based on clinical evaluation methods for new antimicrobal agents [11].

\section{RESULTS}

Table 1 shows the clinical features of acute respiratory infection caused by the Streptococcus milleri group. Streptococcus milleri pulmonary infection

TABLE 1.

Characteristics of patients with respiratory infections caused by Streptococcus milleri

\begin{tabular}{|c|c|c|c|c|c|c|c|c|}
\hline Case & Age & Sex & Diagnosis & $\begin{array}{l}\text { Associated } \\
\text { organisms }\end{array}$ & $\begin{array}{l}\text { Underlying } \\
\text { disease }\end{array}$ & $\begin{array}{l}\text { Severity of } \\
\text { infection }\end{array}$ & Treatment & Evolution \\
\hline 1 & 77 & M & pneumonia & p. aureginosa & lung cancer & severe & cefozopran & death \\
\hline 2 & 77 & $\mathbf{M}$ & pneumonia, pleuritis & $(-)$ & $\begin{array}{l}\text { pulmonary emphysema, } \\
\text { liver cirrohsis }\end{array}$ & severe & flomoxef & death \\
\hline 3 & 79 & $\mathrm{~F}$ & pneumonia & $(-)$ & bronchiectasis & moderate & sulbactam/cefoperazon & cured \\
\hline 4 & 87 & $\mathrm{~F}$ & lung abscess & $(-)$ & $(-)$ & moderate & ceftazidime + clindamycin & cured \\
\hline 5 & 80 & $\mathrm{~F}$ & pneumonia & $(-)$ & $(-)$ & mild & cefotiam & cured \\
\hline 6 & 79 & M & pneumonia & $(-)$ & $(-)$ & mild & piperacillin & cured \\
\hline 7 & 91 & M & pneumonia & $(-)$ & heart failure & mild & cefotiam & cured \\
\hline 8 & 79 & M & pneumonia & $(-)$ & bronchiectasis & moderate & ceftazidime & cured \\
\hline 9 & 75 & $\mathrm{M}$ & pneumonia & p. aureginosa & $\begin{array}{l}\text { pulmonary emphysema, post } \\
\text { operation of colon ca }\end{array}$ & severe & imipenem + clindamycin & death \\
\hline 10 & 65 & $\mathrm{~F}$ & pneumonia & $(-)$ & $(-)$ & mild & cefotiam & cured \\
\hline 11 & 78 & M & pneumonia, pleuritis & $(-)$ & lung cancer & moderate & sulbactam/cefoperazon & cured \\
\hline 12 & 79 & $\mathrm{~F}$ & pneumonia & $(-)$ & $(-)$ & moderate & cefotiam & cured \\
\hline 13 & 79 & M & empyema & $\begin{array}{l}\text { prevotella } \\
\text { intermedia }\end{array}$ & pulmonary emphysema & severe & meropenem + clindamycin & n cured \\
\hline 14 & 77 & M & pneumonia & $(-)$ & pulmonary emphysema & mild & sulbactam/cefoperazon & cured \\
\hline 15 & 73 & $\mathbf{M}$ & lung abscess & $\begin{array}{l}\text { bacteroides } \\
\text { frailis }\end{array}$ & pulmonary emphysema & moderate & ceftazidime + clindamycin & n cured \\
\hline 16 & 80 & M & bronchitis & $(-)$ & bronchiectasis, DM & mild & cefotiam & cured \\
\hline 17 & 70 & M & pneumonia & $(-)$ & $\begin{array}{l}\text { chronic hepatitis type } \mathrm{C} \text {, } \\
\text { DM }\end{array}$ & moderate & sulbactam/cefoperazon & cured \\
\hline 18 & 74 & $\mathrm{~F}$ & pneumonia & $(-)$ & old pulmonary tuberculosis & mild & piperacillin & cured \\
\hline 19 & 65 & M & pneumonia & $(-)$ & $\begin{array}{l}\text { chronic hepatitis type C, } \\
\text { DM }\end{array}$ & severe & panipenem & cured \\
\hline
\end{tabular}


was identified in 19 patients, 13 men and 6 women, whose ages ranged from 65 to 91 years old. Thirteen of these patients had pneumonia, two had contaminant pneumonia and pleuritis, one had bronchitis, two had a lung abscess, and one had empyema. Severe, moderate and mild infections were observed in 5, 7 and 7 patients, respectively. None of them had bacteremia. Underlying diseases are also described in Table 1. They included 11 cases of pulmonary pathologies (lung cancer in 2 cases, pulmonary emphysema in 5 cases, bronchiectasis in 3 cases and history of pulmonary tuberculosis in 1 case), three of diabetes mellitus, three of liver disease and one of heart disease. However, five patients had no underlying diseases and none of them was alcoholic.

Microbiological diagnosis was made by culture of pleural exudate in 3 cases (patients 2, 11 and 13) and of bronchial lavage in 3 cases (patients 1, 11 and 14) (Table 1). Other cases of pneumonia or bronchitis were diagnosed based on the results of aspirated sputum culture. In 4 of the 19 cases, the infection was polymicrobial in nature. In infections related to a thoracic procedure, other organisms were also isolated: Pseudomonas aeruginosa and anaerobic bacteria (patients 1, 9, 13 and 15).

Antibiotics such as penicillin, cefem, carbapenem and clindamycin were administered to all patients. All the Streptococcus milleri isolates were suscepti- ble to these antibiotics. With regard to evolution, 16 patients werer cured and three patients died.

Table 2 shows the laboratory data and body temperature of the 19 patients. Severe cases tended to have a high WBC count, a high CRP value and high fever.

\section{DISCUSSION}

The Streptococcus milleri group is part of the usual flora of the mouth, but its actual prevalence is unknown. It is also found in normal faecal flora in $16-67 \%$ of healthy adults and has been isolated from normal appendix and from vaginal secretions [1214]. The most important clinical feature of these microorganisms is their tendency to cause various suppurative infections such as dental abscesses or deep visceral abscesses $[3,15,16]$.

In this study, of the various types of thoracic infections caused by Streptococcus milleri, empyema and lung abscesses were found to be the most common. This result agrees with previous reports by other authors $[15,17,18]$. Predisposing factors which have been associated with Streptococcus milleri, empyema and lung abscesses include mucosal disturbance (sinusitis, periodontal disease, enteric disease such as esophageal perforation), thoracic surgery, malignancy, neurological disease, alcohol abuse, and

TABLE 2.

Laboratory findings in 19 patients with Streptococcus milleri infection

\begin{tabular}{crrccc}
\hline Case & $\begin{array}{c}\text { WBC } \\
(/ \mu \mathrm{l})\end{array}$ & $\begin{array}{c}\text { CRP } \\
(\mathrm{mg} / \mathrm{dl})\end{array}$ & $\begin{array}{c}\text { Total protein } \\
(\mathrm{g} / \mathrm{dl})\end{array}$ & $\begin{array}{c}\text { Albumin } \\
(\mathrm{g} / \mathrm{dl})\end{array}$ & $\begin{array}{c}\text { Body temperature } \\
\left({ }^{\circ} \mathrm{C}\right)\end{array}$ \\
\hline 1 & 17270 & 14.4 & 6.8 & 3.0 & 38.6 \\
2 & 15540 & 22.8 & 4.8 & 2.8 & 38.8 \\
3 & 10940 & 9.6 & 5.9 & 2.8 & 37.5 \\
4 & 9090 & 13.0 & 6.3 & 3.0 & 37.6 \\
5 & 10340 & 3.6 & 6.4 & 3.4 & 37.4 \\
6 & 8600 & 3.5 & 6.7 & 4.2 & 37.5 \\
7 & 6310 & 3.6 & 5.9 & 3.3 & 38.0 \\
8 & 9090 & 21.6 & 5.9 & 3.2 & 38.4 \\
9 & 15570 & 18.7 & 6.4 & 4.2 & 37.2 \\
10 & 8600 & 8.5 & 6.2 & 3.3 & 37.6 \\
11 & 11720 & 5.9 & 6.1 & 3.4 & 38.8 \\
12 & 14650 & 12.2 & 5.6 & 3.0 & 37.4 \\
13 & 19020 & 23.3 & 5.6 & 3.2 & 37.8 \\
14 & 7780 & 3.8 & 7.1 & 3.3 & 38.4 \\
15 & 14960 & 18.3 & 6.1 & 4.1 & 37.8 \\
17 & 11690 & 3.2 & 6.4 & 4.2 & 38.4 \\
18 & 13600 & 10.3 & 6.6 & 2.3 & \\
\hline
\end{tabular}


diabetes $[4,6,7,19]$. Further, the underlying diseases observed were periodontal disease, diabetes mellitus, neoplasm, alcoholism, HIV infection and chronic obstructive disease; these associations have been recognized previously $[3,20,21]$. Our present study included only two cases of lung abscesses and one of empyema; most of the patients suffered from pneumonia. It is noteworthy that some of these cases of pneumonia were found in elderly people with neither underlying disease nor any predisposing factor.

Shinzato et al. [7」 reported a possible synergy between the Streptococcus milleri group and anaerobic bacteria. The former organisms are often involved in mixed infections and their particularly frequent isolation in combination with anaerobic bacteria suggests synergy. It was also suggested that anaerobic bacteria might stimulate the growth of the Streptococcus milleri group and suppress the bactericidal activity of host cells [7]. In our study, we found two cases of mixed infections caused by Streptococcus milleri and anaerobic bacteria (patients 13 and 15). One had empyema and the other a lung abscess. We considered that these mixed infections might be one of the risk factors contributing to the severity of the infection, as suggested previously $[3,7,22]$. Furthermore, we had two patients with severe mixed infections caused by Streptococcus milleri and P.aeruginosa (patients 1 and 9). Patients with mixed pulmonary infections caused by Streptococcus milleri and another bacterial strain must be observed carefully. Our experience indicates that such mixed infections might be lifethreatening.

Several authors have reported the results of treatment with antibiotics for infections caused by the Streptococcus milleri group and the susceptibility of the bacteria to some antibiotics $[4,18,20,21,23]$. There have been cases of resistance to penicillin $[8,24]$, however, fortunately none of the isolates in our study showed decreased susceptibility to antibiotics (penicillin, $\beta$-lactam and clindamycin). Nevertheless, it is important to be aware of a possible resistance to antibiotics, and this may well become a more serious problem in the future.

It was reported that Streptococcus milleri was causative pathogen in about $3-15 \%$ of the cases of community-acquired peumonia $[25,26]$. We had 15 cases of pneumonia associated with Streptococcus milleri in the elderly. We adopted the Japanese guidelines for the diagnosis of acute pneumonia and bronchitis caused by Streptococcus milleri in our study. However, it might be difficult to diagnose
Streptococcus milleri infections simply by examining sputum specimens. A further investigation will be needed to be clarify diagnostic methods.

In this study, we reviewed 19 cases of acute respiratory infections caused by Streptococcus milleri. Although thoracic infections associated with Streotococcus milleri such as empyema and lung abscess are common, there were 15 cases of pneumonia among the 19 patients evaluated in this study. It has been shown that most such patients have underlying diseases or are alcoholics. However, we had 5 patients with no underlying disease and none of these five was alcoholic. Streptococcus milleri might become an important cause of acute pneumonia in patients of advanced age. The key principles of management of Streptococcus milleri infection are early diagnosis and control of the infection with appropriate antibiotics. It is important to select suitable antibiotics for these infections and prevent the progression to empyema or lung abscess, particularly in the case of mixed infections. We should be extremely careful in our management of mixed infections because of their severity.

We conclude that Streptococcus milleri must be recognized as a very important pathogen causative of acute respiratory infections, especially in elderly patients. Further prospective investigations are needed to provide additional details on the role of the Streptococcus milleri group in pneumonia and other lower respiratory tract infections.

\section{REFERENCES}

1. Isenberg HD, and D'Amato RF. Indigenous and pathogenic microorganisms of humsans. In: Manual of Clinical Microbiology, ed. Murray PR, Baron EJ, Pfaller MA, Tenover FC and Yolken RH, American Society for Microbiology, Washington DC, pp5-18, 1995.

2. Coykendall AL. Classification and identification of the viridas streptcocci. Clin Microbiol Rev 1989; 2:315-328.

3. Gossling J. Occurrence, and pathogenicity of the Streptococcus milleri group. Rev Infect Dis 1988; 10:257-285.

4. Hocken DB, and Dussek JE. Streptococcus milleri as acause of pulmonary empyema. Thorax 1985; 40:626628.

5. Waitkins SA, Ratcliffe JG, and Roberts C. Streptococcus milleri found in pulmonary empyema and abscess. J Clin Pathol 1985; 38:716-717.

6. Ferber Th, Muller F, and Graevenittz Av. Pleuraempyema mit Streptococcus milleri. Schweiz Med Wschr 1987; 117:916-919.

7. Shinzato T, Uema H, Inadome J, Shimoji K, Kusano N et al. Bacteriological and clinical studies in 23 cases 
thoracic empyema: the role of oral streptococci and anaerobes. Nippon Kyobu Shikkan Gakkai Zasshi 1993; 31:486-491. (in Japanese)

8. Fujiki R, Kawayama T, Rikimaru T, and Oizumi K. A Three-years series of Acute Respiratory Tract Infections Caused by Streptococcus milleri group. J J Assoc Infect Dis 2002; 76:174-179. (in Japanese)

9. Touyama M, and Saitoh A. Streptococcus milleri infections. Modern Physician 1997; 17:869-872. (in Japanese)

10. Yamashiro T. Studies on Clinical Significance of "Steptococcus milleri group" in respiratory Infections. J J Assoc Infect Dis 1991; 65:1419-1429. (in Japanese)

11. Saito A. Clinical evaluation methods for new antimicrobial agents to treat respiratory infections. J Infect Chemother 1995; 5:110-123.

12. Whiley R, Fraster $\mathrm{H}$, Hardia $\mathrm{M}$, and Beighton $\mathrm{D}$. Phenotypic differentiation of Streptococcus intermedius, Streptococcus constellatus, and Streptococcus angiosus. Strains within the "Streptococcus milleri group”. J Clin Microbiol 1990; 28:1497-1501.

13. Piscitelli C, Swed J, Schreckenberger P, and Danziger LH. Streptococcus milleri group: renewed interest in an elusive pathogen. Eur J Clin Microbial Infect Dis 1992; 11:491-498.

14. Anonymous. Streptococcus milleri, pathogen in various guises. Lancet 1985; 9:275-302.

15. Parker MT, and Ball LC. Storeptococci and aerococci associated with systemic infection in man. $\mathrm{J}$ Med Microbiol, Vol 9, pp275-302, 1976.

16. Poole PM, and Wilson G. Occurrence and cultural features of Streptococcus milleri in various body sites. J Clin Pathol 1979; 32:764-768.

17. Molina F, and Duran MT. Caracteristias microbiologicas yespectro de infecciones de 108 Streptcoccus anginosus aislados. Enferm Infecc Microbiol Clin 1993; 11:304308.

18. Molina JM, Leport C, Bure A, Wolff M, Michon C et al. Clinical and bacterial feature of infections caused by Streptococcus milleri. Scand J Infect Dis 1991; 23:659666.

19. Roy WJ Jr, and Roy TM. Thoracic empyema due to Streptococcus intermedius. Kentucky Med Assoc 1991; 89:558-562.

20. Shales DM, Lerner PI, Wolinsky E, and Gopalakrishna $\mathrm{KV}$. Infections due to Lancefield group $\mathrm{F}$ and related strepto-cocci (S.milleri, S. anginosus). Medicine 1981; 60:197-207.

21. Jacobs JA, Pietersen HG, Stobberingh EE, and Soeters PB. Bacteriemia involving the "Streptococcus milleri group" group: analysis of 19 cases. Clin Infect Dis 1994; 19:704-713.

22. Shinzato T, and Saito A. A mechanism of pathogenicity of "Streptococcus milleri group" in pulmonary infection : synergy with an anearobe. J Med Microbiol 1994; 40:118-123.

23. Wong CA, Donald F, and Macfarlane JT. Streptococcus milleri pulmonary disease: a review and clinical description of 25 patients. Thorax 1995; 50:1093-1096.

24. Porta G, Rodriguez-Carballeira M, Gome L, Salavert M, Freixas $\mathrm{N}$ et al. Thoracic infection caused by Streptococcus milleri. Eur respir J 1998; 27:357-362.

25. Shinzato T, and Saito A. The Streptococcus milleri group as a cause of pulmonary infections. Clin Infec Dis 1995; 21:238-243.

26. Ishida T, Hashimoto T, Aratani M, Ito I, Osawa $\mathrm{H}$ et al. Etiology of community-acquired peumonia in hospitalized patients. A 3-year prospective study in Japan. Chest 1998; 114:1588-1593. 